\title{
Polish version of the Parental Stressor Scale: Neonatal Intensive Care Unit
}

\author{
Anna Aftyka',A-E, Ilona Rozalska', ${ }^{1, B}$, Beata Rybojad ${ }^{2, B, E}$, Marzena Elżbieta Samardakiewicz ${ }^{3, B, E-F}$ \\ ${ }^{1}$ Department of Anaesthesiological and Intensive Care Nursing, Faculty of Health Sciences, Medical University, Lublin, \\ Poland \\ ${ }^{2}$ Department of Qualified Medical Aid, Faculty of Health Sciences, Medical University, Lublin, Poland \\ ${ }^{3}$ Department of Applied Psychology, Medical University, Lublin, Poland \\ A - Research concept and design, B - Collection and/or assembly of data, C - Data analysis and interpretation, \\ $D$ - Writing the article, E - Critical revision of the article, F - Final approval of article
}

\begin{abstract}
Aftyka A, Rozalska I, Rybojad B, Samardakiewicz ME. Polish version of the Parental Stressor Scale: Neonatal Intensive Care Unit. Ann Agric
\end{abstract} Environ Med. 2019; 26(1): 67-72. doi: 10.26444/aaem/89769

\begin{abstract}
Introduction. Parental Stressor Scale: Neonatal Intensive Care Unit (PSS:NICU) by M. Miles et al. has been developed in order to assess the stress experienced by parents of infants being treated in Intensive Care Units. The measurement of parental stress enables the evaluation of nursing care effectiveness, as well as facilitating the determination of the level of progress made by parents in coping with the difficult situation they face.

Objectives. The aims of the research include: (1) validation of the Parental Stressor Scale: Neonatal Intensive Care Unit Polish Version and (2) initial assessment of perceptions of parental stress in a group of 151 parents of infants treated in four NICUs in Poland.

Materials and method. This quantitative cross-sectional study was performed among 151 parents (129 mothers and 22 fathers) of infants treated in four NICUs in central and eastern Poland. The respondents were asked to complete forms following the Parental Stressor Scale: Neonatal Intensive Care Unit, the Impact Event Scale - Revised (IES-R), and their demographics, which combined basic medical data along with socio-demographic data of both parents and children.

Results. The three sub-scales distinguished on the basis of factor analysis (Infant Appearance, Parental Role Alteration, Sights and Sounds) explain in total $54.89 \%$ of variances. Cronbach's alpha for the entire scale equals 0.92 , while as follows for the particular sub-scales: Infant Appearance - 0.92; Parental Role Alteration - 0.86, and Sights and Sounds - 0.78.

Conclusions. The Polish version of PSS:NICU is an accurate and reliable tool for the assessment of stress experienced by parents whose infants require treatment in NICUs.
\end{abstract}

\section{Key words}

newborn, NICU, distress, parental stress, pre-term infant

\section{INTRODUCTION}

Pregnancy is a period when parents prepare themselves for the birth of their baby, imagining what its appearance and behaviour will be. During this time, a bond is created between them and the unborn baby. The birth of the child then provides a new dimension. The process of appreciating a newborn is affected by features such as gender, body size and shape, condition, appearance and behaviour. If a discrepancy between parental expectations and the child's actual physical state exists, for instance, when a baby is born with congenital defects or pre-term, parents suffer acute stress [1]. The treatment of a baby in the NICU places parents in a number of difficult situations. These are associated with the sounds and environment of the NICU, the frail appearance of the newborn and the long-term physical separation. The high level of stress following pre-term delivery can lead to severe mental disorders, including acute stress disorder (ASD), post-traumatic stress disorder (PTSD), depression, and other complications [2-7]. For example, the frequency rate of postpartum depression (PPD) in mothers of premature babies

Address for correspondence: Marzena Elżbieta Samardakiewicz Dept. of Applied Psychology, Uniwersytet Medyczny w Lublinie, ul. Witolda Chodźki 7, 20-093 Lublin, Poland

e-mail: psychonk@dsk.lublin.pl

Received: 31.01.2018; accepted: 06.04.2018; first published: 17.05.2018 is $30-40 \%$, while for the population of mothers of healthy newborns delivered at term this is as low as $6-12 \%$ [8]. It may be that the mothers' emotional state may influence the integrity of their attachment to their neonates, which can considerably impact the emotional, social and cognitive development of the baby [9].

The scale of stress in parents whose infants were treated in the Neonatal Intensive Care Units (PSS:NICU) was compiled by $\mathrm{M}$. Miles et al., in order to measure the stress experienced by parents during their children's NICU treatment. It consists of the following three sub-scales: (1) Parental Role Alteration, (2) Infant Appearance, (3) Sights and Sounds encountered in NICUs. The PSS:NICU questionnaire, completed by the parents, aims at evaluating how stressful they perceive each of these situations on a scale of $1-5$, with 1 being the least stressful and 5 the most stressful. If a situation is not relevant to a respondent, they may mark it as N/A (not applicable) [10].

The measurement of parental stress enables evaluation of the effectiveness of nursing care, as well as assisting specialists with monitoring parents' progress in coping with the difficult situations they have to face $[11,12]$. PSS:NICU is applied all over the world and has been translated into many different languages, including English, Italian, Swedish, Korean, Turkish and Arab [2, 13-17]. However, a standardised tool that enables the assessment of the perceived stress of parents of infants hospitalised in the NICU is not available in 
Poland. Thus, a culturally sensitive adaptation of PSS:NICU is justified, along with assessment of the validity and reliability of this Polish version.

\section{OBJECTIVE}

The aims of the research include: (1) validation of the Parental Stressor Scale: Neonatal Intensive Care Unit in Polish and (2) initial assessment of perceptions of parental stress in a group of 151 parents of infants treated in four NICUs in Poland.

\section{MATERIALS AND METHOD}

Study sample. The quantitative cross-sectional study was performed among 151 parents (129 mothers and 22 fathers) of children treated in NICUs in central and eastern Poland. The minimum study sample size was 130 and was estimated by multiplying the number of questionnaire items (26) by five [18] The inclusion criteria were as follows: a minimum one-day hospital treatment of a biological child on the day the survey was conducted, the supply of personal care to the hospitalised child, provision of informed consent for participating in the survey, and being literate in Polish.

Study settings. The data was collected from the parents of children treated in four NICUs located in central and eastern Poland. The research was carried out in two NICUs of secondary care and two NICUs of tertiary care. The latter provided advanced treatments, namely surgical treatment including cardio-surgery, therapeutic hypothermia or nitric oxide therapy.

Description of data collection tool. Having received permission from the author of PSS:NICU, Professor Margaret S. Miles, to compile a Polish version, a multi-stage adaptation procedure was instituted. The Polish translation of PSS:NICU was conducted in line with the approved rules of transcultural adaptation [19]. The translation of the instrument into Polish involved three independent translators, whose translations were compared and assessed to compile a single draft version. This draft was evaluated by ten parents acquainted with the Polish version of the scale in order to introduce refinements. Afterwards, an expert assessment was carried out by an anaesthetist, a nurse specialist in anaesthesiology and intensive care, a psychologist, a Polish philologist (MA) and the parent of a child treated in hospital. The experts evaluated every statement in terms of the following criteria: intelligibility, comprehensibility and ambiguity. Having made improvements, the tool was assessed again to meet the aforementioned criteria. In order to ensure the highest quality of the translation, this final version of the instrument was compared with the original one in terms of semantic equivalence by a translator who had not participated in the process, as well as by experts in language adaptation. At the next stage, the tool was back-translated, namely re-translated into its original language by another translator who had not taken part in the original translation. It was confirmed that the obtained versions were equivalent.

Data collection tool. The two questionnaires were completed by the respondents during the stay of infants in hospital. The first questionnaire constituted the Polish version of PSS:NICU, which is a self-report instrument of 26 items assessing the severity of parental stress caused by a newborn's hospital treatment in an NICU. A high score on PSS:NICU proves considerable stress intensity resulting from the child's NICU treatment. The second questionnaire on demographics was created by the authors for the collection of basic medical and socio-demographic data of both parents and their children. The parents provided information about their gender, age, education and place of residence. The questions regarding the children referred to their birth weight, gestational age and duration of hospital treatment.

Data collection methods. The questionnaires were handed to the parents by specially trained doctors, nurses and nursing students. The parents were provided with comprehensive information about the survey and were asked to give consent for their participation in the study. If they confirmed their willingness to participate, they were requested to sign an informed consent form and received the questionnaires in an envelope. Having completed the questionnaires, the parents returned them in a sealed envelope.

Ethical Approval. Following the Guidelines for Good Clinical Practice, the Ethical Committee of the Medical University in Lublin approved the study protocol on 27 March 2014 (KE-0254/78/2014).

Statistical analysis. The characteristics of validation were compiled based on an analysis of percentage distribution of the frequency of qualitative variables, as well as on values of descriptive statistics - namely the mean, standard deviation, minimum and maximum of the quantitative variables. The construct validity of the scale was estimated by means of exploratory factor analysis (EFA), where direct Oblimin rotation was used, as well as by means of confirmatory factor analysis (CFA). The reliability and internal consistency of PSS:NICU were assessed by computing the discrimination power of the items constituting the particular dimensions of the verified research tool and Cronbach's alpha. The borderline level of type I error, equal to 0.05, was assumed in the analyses conducted. Statistical calculations were performed using the IBM SPSS AMOS 21 software.

\section{RESULTS}

The validation sample was recruited intentionally and included 129 mothers (85.4\%) and 22 fathers (14.6\%) of newborns treated in NICU. The vast majority of parents were in middle adulthood $(\mathrm{N}=124 ; 82.1 \%)$. Most of the respondents $(\mathrm{N}=89 ; 58.9 \%)$ had received higher education. A total of $62.3 \%(\mathrm{~N}=94)$ of the participants came from urban areas, while $35.1 \%(\mathrm{~N}=53)$ lived in rural areas. Mothers and fathers who were rearing two children constituted the highest percentage $(\mathrm{N}=67 ; 44.4 \%)$, while those who were bringing up one child constituted $41.1 \%$. A total of $14.6 \%$ of those surveyed $(\mathrm{N}=22)$ had three or four children. On average, the women had been pregnant twice $(\mathrm{M}=2.10$; $\mathrm{SD}=1.18$; $\mathrm{Min}=1$; $\mathrm{Max}=7)$. More than half of the women $(\mathrm{N}=82 ; 54.3 \%)$ had their last delivery by Caesarean section. The mean gestational age of the infants was 36.5 weeks $(M=36.47 ; \mathrm{SD}=3.24)$ with the shortest pregnancy being 26 weeks and the longest 42 
weeks ( $M i n=26 ; \operatorname{Max}=42$ ). The average amount of points for the infants was slightly above 8 Apgar Score $(M=8.23$; $\mathrm{SD}=2.12)$. The scale points ranged from $0-10(\mathrm{Min}=0$; $\mathrm{Max}=10)$. The average neonatal birth weight was 2,844 grams $(\mathrm{M}=2,844 ; \mathrm{SD}=790)$, with the lowest being $970 \mathrm{~g}$ and the highest $4,650 \mathrm{~g}$. The average duration of hospital treatment up to the completion of the questionnaire was 19 days $(\mathrm{M}=19.1$; $\mathrm{SD}=15.3$ ). The shortest hospital stay in NICU lasted one day and the longest ninety days. The infants were diagnosed with cardiovascular diseases $(\mathrm{N}=39 ; 25.8 \%)$, respiratory diseases $(\mathrm{N}=43 ; 28.5 \%)$ and congenital defects $(\mathrm{N}=19 ; 12.6 \%)$, while two infants had undergone surgery (1.3\%) (Tab. 1).

Table 1. Characteristics of the validation sample, $N=151$

\begin{tabular}{|c|c|c|c|}
\hline Variables & & $N$ & $\%$ \\
\hline \multirow{2}{*}{ Gender } & Females & 129 & 85.4 \\
\hline & Males & 22 & 14.6 \\
\hline \multirow{3}{*}{ Adult development } & Early adulthood $18-24$ years old & 17 & 11.3 \\
\hline & Middle adulthood 25-39 years old & 124 & 82.1 \\
\hline & Late adulthood $40-59$ years old & 10 & 6.6 \\
\hline \multirow{4}{*}{ Education } & Primary & 4 & 2.6 \\
\hline & Secondary & 55 & 36.4 \\
\hline & Higher & 89 & 58.9 \\
\hline & No data & 3 & 2.0 \\
\hline \multirow{3}{*}{ Place of residence } & Urban areas & 94 & 62.3 \\
\hline & Rural areas & 53 & 35.1 \\
\hline & No data & 4 & 2.6 \\
\hline \multirow{3}{*}{ Offspring } & One & 62 & 41.1 \\
\hline & Two & 67 & 44.4 \\
\hline & Three/four & 22 & 14.6 \\
\hline \multirow{2}{*}{ Delivery } & Natural & 67 & 44.4 \\
\hline & Caesarean section & 82 & 54.3 \\
\hline \multirow{4}{*}{ Diagnosis } & Cardiovascular diseases & 39 & 25.8 \\
\hline & Respiratory diseases & 43 & 28.5 \\
\hline & Congenital defects & 19 & 12.6 \\
\hline & Surgery & 2 & 1.3 \\
\hline
\end{tabular}

Exploratory factor analysis was conducted with the application of the principal components method with direct Oblimin rotation, in order to verify the construct validity of the PSS:NICU. The use of rotation for correlated variables was dictated by conceptual assumptions that accept the concurrence of the analysed sources of stress in the mothers and fathers of babies treated in NICUs. The analyses performed led to the identification of three factors that explain in total $54.89 \%$ of variances. A total of 13 out of 26 items make up factor 1 that explains $35.64 \%$ of variances. Factor 2 comprises seven items and explains $11.34 \%$ of variances. Factor 3 includes six items and explains 7.92\% of variances. Factor 1 refers to stress associated with Infant Appearance. Factor 2 is characterised by stress linked to Parental Role Alteration. Factor 3 allows the determination of stress severity caused by Sights and Sounds encountered in NICUs. The differentiated sub-scale of Parental Role Alteration is consistent with the original tool composed of seven items. Originally, the sub-scale Infant Appearance consisted of fourteen items, but was subsequently shortened into a 13-item one when item No. 8 was included in Sights and Sounds. Table 2 shows the particular values of factor loadings for the 26 items obtained in the last step of the factor analysis and included in the different sub-scales.

Table 2. Factor loadings for PSS: NICU, N=151 - exploratory factor analysis

\begin{tabular}{|c|c|c|c|}
\hline Item & $\begin{array}{c}\text { Factor 1: } \\
\text { Infant Appearance }\end{array}$ & $\begin{array}{c}\text { Factor 2: } \\
\text { Parental Role Alteration }\end{array}$ & $\begin{array}{c}\text { Factor 3: } \\
\text { Sights and Sounds }\end{array}$ \\
\hline 15 & 0.87 & & \\
\hline 16 & 0.81 & & \\
\hline 12 & 0.80 & & \\
\hline 17 & 0.78 & & \\
\hline 19 & 0.76 & & \\
\hline 13 & 0.71 & & \\
\hline 18 & 0.66 & & \\
\hline 10 & 0.64 & & \\
\hline 9 & 0.64 & & \\
\hline 14 & 0.60 & & \\
\hline 6 & 0.52 & & \\
\hline 11 & 0.49 & & \\
\hline 7 & 0.42 & & \\
\hline 22 & & 0.86 & \\
\hline 21 & & 0.81 & \\
\hline 20 & & 0.77 & \\
\hline 23 & & 0.76 & \\
\hline 25 & & 0.68 & \\
\hline 26 & & 0.59 & \\
\hline 24 & & 0.51 & \\
\hline 5 & & & 0.87 \\
\hline 4 & & & 0.70 \\
\hline 2 & & & 0.67 \\
\hline 1 & & & 0.52 \\
\hline 3 & & & 0.47 \\
\hline 8 & & & 0.44 \\
\hline
\end{tabular}

Confirmatory factor analysis (CFA) was also conducted in order to verify factor validity of the Polish version of PSS: NICU. The analyses were carried out on a raw data matrix using Maximum Likelihood Estimation (MLE).

The constructed model of the adapted scale is depicted in graphic form in Figure 1, whereas Table 3 includes standardized values of factor loadings, correlation coefficients among the distinguished factors and multiple correlation coefficients $\mathrm{R}^{2}$. Analysis of the model fit to data indicated that the model reflected the character of relationships between the variables considered. The correction for model complexity CMIN/DF amounted to 1.10 which did not exceed Hoelter's critical $\mathrm{N}$ of 2 and equalled 236 for a 95\% confidence level, and 292 for a $99 \%$ confidence level; thus, it confirmed the model fit. The Root Mean Squared Error of Approximation (RMSEA) was classified in the range of $0.00-0.08$ and showed acceptable confidence for the model constructed. The Goodness of Fit Index (GFI) and the Adjusted Goodness of Fit Index (AGFI) equalled 0.97 and 0.94 , respectively, while the Comparative Fit Index (CFI) attained a value of 0.99 , indicating an appropriate model reflection of the character of relationships occurring in the population. The level of 
Table 3. Loading factors, values of $R^{2}$ coefficients and correlations for PSS:NICU, N=151, confirmatory factor analysis

\begin{tabular}{|c|c|c|c|c|c|c|}
\hline \multirow[t]{2}{*}{ Item } & \multicolumn{2}{|c|}{$\begin{array}{c}\text { Factor 1: } \\
\text { Infant Appearance }\end{array}$} & \multicolumn{2}{|c|}{$\begin{array}{l}\text { Factor 2: } \\
\text { Parental Role } \\
\text { Alteration }\end{array}$} & \multicolumn{2}{|c|}{$\begin{array}{c}\text { Factor 3: } \\
\text { Sights and Sounds }\end{array}$} \\
\hline & SRW & $R^{2}$ & SRW & $R^{2}$ & SRW & $R^{2}$ \\
\hline 15 & 0.77 & 0.59 & & & & \\
\hline 16 & 0.74 & 0.55 & & & & \\
\hline 12 & 0.80 & 0.63 & & & & \\
\hline 17 & 0.78 & 0.61 & & & & \\
\hline 19 & 0.69 & 0.47 & & & & \\
\hline 13 & 0.73 & 0.53 & & & & \\
\hline 18 & 0.71 & 0.51 & & & & \\
\hline 10 & 0.61 & 0.38 & & & & \\
\hline 9 & 0.63 & 0.39 & & & & \\
\hline 14 & 0.69 & 0.47 & & & & \\
\hline 6 & 0.62 & 0.38 & & & & \\
\hline 11 & 0.51 & 0.26 & & & & \\
\hline 7 & 0.37 & 0.14 & & & & \\
\hline 22 & & & 0.85 & 0.73 & & \\
\hline 21 & & & 0.76 & 0.58 & & \\
\hline 20 & & & 0.66 & 0.43 & & \\
\hline 23 & & & 0.77 & 0.60 & & \\
\hline 25 & & & 0.62 & 0.39 & & \\
\hline 26 & & & 0.50 & 0.25 & & \\
\hline 24 & & & 0.52 & 0.27 & & \\
\hline 5 & & & & & 0.48 & 0.24 \\
\hline 4 & & & & & 0.50 & 0.25 \\
\hline 2 & & & & & 0.88 & 0.77 \\
\hline 1 & & & & & 0.84 & 0.70 \\
\hline 3 & & & & & 0.70 & 0.48 \\
\hline 8 & & & & & 0.34 & 0.11 \\
\hline Correlations & Pare & | Role Alt & ation & & hts and $\mathrm{S}$ & \\
\hline Infant Appearance & & $0.48^{*}$ & & & $0.65^{*}$ & \\
\hline Sights and Sounds & & $0.32^{*}$ & & & & \\
\hline
\end{tabular}

SRW - Standarized regression weighs; $R^{2}$ - Squared Multiple Correlations; ${ }^{*}-\mathrm{p}<0.001$

significance for the model fit PCLOSE was not statistically significant (0.67) and also confirmed the fitness of the model.

The analyses conducted indicated that standardized path coefficients ranged from $0.80-0.37$ for the Infant Appearance sub-scale, they remained within the range of $0.085-0.50$ for the Parental Role Alteration sub-scale, and were within the range of $0.88-0.34$ for the Sights and Sounds sub-scale. This constitutes an acceptable result. Each of the path coefficients considered was statistically significant, $\mathrm{p}<0.001$.

The percentage of the variance explained for particular factor loadings exceeded a value of 0.5 for those items whose loads were above 0.7. In turn, for the remainder, the value remained in the range of $0.48-0.11$, which can be recognized as an acceptable result. On this basis, it can be stated that the model constructed is acceptable and confirms the threefactor structure of the scale that was distinguished by means of the exploratory factor analysis.

The reliability of PSS:NICU was estimated on the basis of information about the discrimination power of items
Table 4. Discrimination power of items included in PSS:NICU dimensions, $\mathrm{N}=151$

\begin{tabular}{|c|c|c|c|}
\hline Scale & $\begin{array}{c}\text { Item } \\
\text { PSS: NICU }\end{array}$ & $\begin{array}{l}\text { Discrimination } \\
\text { power of item }\end{array}$ & $\begin{array}{l}\text { Cronbach alpha } \\
\text { after removal of item }\end{array}$ \\
\hline \multirow{13}{*}{$\begin{array}{l}\text { Infant } \\
\text { Appearance }\end{array}$} & 15 & 0.76 & 0.91 \\
\hline & 16 & 0.74 & 0.91 \\
\hline & 12 & 0.73 & 0.91 \\
\hline & 17 & 0.74 & 0.91 \\
\hline & 19 & 0.66 & 0.91 \\
\hline & 13 & 0.68 & 0.91 \\
\hline & 18 & 0.64 & 0.91 \\
\hline & 10 & 0.63 & 0.91 \\
\hline & 9 & 0.62 & 0.91 \\
\hline & 14 & 0.61 & 0.92 \\
\hline & 6 & 0.66 & 0.91 \\
\hline & 11 & 0.52 & 0.92 \\
\hline & 7 & 0.49 & 0.92 \\
\hline \multirow{7}{*}{$\begin{array}{l}\text { Parental Role } \\
\text { Alteration }\end{array}$} & 22 & 0.78 & 0.82 \\
\hline & 21 & 0.71 & 0.83 \\
\hline & 20 & 0.60 & 0.85 \\
\hline & 23 & 0.70 & 0.83 \\
\hline & 25 & 0.65 & 0.84 \\
\hline & 26 & 0.49 & 0.86 \\
\hline & 24 & 0.51 & 0.86 \\
\hline \multirow{6}{*}{$\begin{array}{l}\text { Sights and } \\
\text { Sounds }\end{array}$} & 5 & 0.55 & 0.73 \\
\hline & 4 & 0.49 & 0.76 \\
\hline & 2 & 0.72 & 0.71 \\
\hline & 1 & 0.65 & 0.72 \\
\hline & 3 & 0.55 & 0.75 \\
\hline & 8 & 0.35 & 0.82 \\
\hline
\end{tabular}

included in the different scales. The analyses revealed high discrimination powers of all the items included in the particular sub-scales. Therefore, it was determined that each item would remain in the identified dimensions. The discrimination power of items in each sub-scale is presented on table 4.

For the whole scale, Cronbach's alpha was 0.92 , for the Infant Appearance sub-scale - 0.92, for the Parental Role Alteration sub-scale -0.86 and for the Sights and Sounds sub-scale -0.78 .

The next stage of the research was directed toward the assessment of parental stress levels in relation to the particular dimensions of PSS:NICU. For parents, Parental Role Alteration was the most stressful $(\mathrm{M}=3.46 ; \mathrm{SD}=1.29)$, followed by Sights and Sounds ( $\mathrm{M}=2.55 ; \mathrm{SD}=1.02)$ and Infant Appearance $(\mathrm{M}=2.33 ; \mathrm{SD}=1.02)$. The average score obtained by parents from the entire scale was 2.68 with a standard deviation of 1.03 .

\section{DISCUSSION}

Internal consistency. The internal consistency of the Polish adaptation of PSS:NICU was high. For the entire scale, Cronbach's alpha was 0.92, for the Infant Appearance subscale -0.92 , for the Parental Role Alteration sub-scale - 0.86, 
and for the Sights and Sounds sub-scale -0.78 . The values of Cronbach's alpha allow for the application of the tool in empirical research and individual diagnosis. The results obtained are slightly higher than those obtained by Iranian researchers $(0.77,0.77$ and 0.86 for each sub-scale respectively: Sights and Sounds, Infant Appearance, and Parental Role Alteration) [13], by American researchers (Sights and Sounds - 0.738, Infant Appearance - 0.861, Parental Role Alteration - 0.847) [2] and by Swedish researchers (Sights and Sounds - 0.644-0.811, Infant Appearance - 0.665-0.745, Parental Role Alteration - 0.811-0.838) [17]. Similar results of Cronbach's alpha were obtained in the Persian version of PSS:NICU (in mothers: Sights and Sounds $=0.88$, Infant Appearance $=0.91$, Parental Role Alteration $=0.87$; in fathers: Sights and Sounds $=0.85$, Infant Appearance $=0.95$, Parental Role Alteration=0.95) [15]. For the entire scale, Cronbach's alpha received in different adaptations ranged from 0.89 in the Italian version [20], to 0.94 in the original American [10] and British [16] versions, and 0.95 in the Korean versions [14].

Factor analysis. The results of the factor analysis of the three versions of PSS:NICU (North American [10], British [16] and Italian [20]) were found in the literature. Similar to the Polish version, the aforementioned versions indicate the three-factor structure of the scale. The three factors of the British version (Infant Appearance, Parental Role Alteration, Sights and Sounds) explain $66 \%$ of variances [16]. The three-factor structure of the Italian adaptation explains $52 \%$ of variances [20]. The Polish version of the three-factor PSS:NICU explains a percentage of variances similar to the above.

An alternative way of interpreting PSS:NICU has been provided by Miles et al. The factor analysis presented in their work revealed the possibility of reducing the number of sub-scales from three to two. Thus, the sub-scale Sights and Sounds (5 items) should be included in the sub-scale Infant Appearance, while the sub-scale Parental Role Alteration (7 items) remains unchanged [21].

Stress perceived by parents of infants treated in NICUs. Previous research on PSS:NICU has shown that the prime source of stress in mothers of infants treated in NICUs is the loss of the parental role, as well as their infant's behaviour and appearance, while the perception of the environment in which the infant is found seems to affect stress levels the least $[2,22,23]$. The presented study demonstrates that the significance of particular stressors can differ slightly in Poland where the average intensity of stress in PSS:NICU was 2.68. This is a substantially lower score than that of Korean researchers, both in mothers and fathers, who scored 3.43 and 3.23, respectively [14]. The presented score is also lower than that obtained by Lau et al. in three similar populations (3.6-3.7) [24]. Higher results were obtained by Busse et al. and Turan et al. who received 3.01, 3.14 and 2.96, respectively $[2,12,25,26]$.

The results obtained in the current study are close to those obtained in the validation research of the original tool, as average stress in PSS:NICU was 2.94 [10]. Similarly, Franck et al. obtained 2.95 [16]. Other researchers obtained results close to those in the current study: Ahn et al. in a group of fathers after educational intervention (2.90) [14], Franck et al. in a group of American parents (2.64) [27], and Alkozei et al. in a group of American mothers (2.99) [28]. Considerably lower results were found in Sweden (1.62), which can be justified by the fact that the vast majority of respondents constituted parents of children treated in secondary care NICUs [17].

In Poland, the most important stressor was Parental Role Alteration (3.46), followed by Sights and Sounds (2.68), and finally, the least significant stressor was Infant Appearance (2.33). To some extent, the results are consistent with the American ones [2, 10, 28]. Lau et al. [24] and Montirosso et al. [20] also obtained similar results in spite of researching three different ethnic groups (African-American, Caucasian, Hispanic).

All research cited is characterised by similar results in the majority of sub-scales, in fact, the differences are minor. The loss of the parental role proved to be the most significant for the participants. There exists, however, a difference regarding the least important factor, which has been shown to be infant appearance, while the presented study indicates the sights and sounds of NICUs. Polish parents are expected to find the appearance and environment of NICUs with the sounds of medical equipment more stressful than the appearance of their infants. This cannot be explained by the fact that infants in Polish NICUs look better, but rather that the environment of the ward is less pleasant or friendly. In the opinions of the authors of the current study, too little attention is paid to silence in Polish NICUs to alleviate the bleakness of the hospital environment for parents. The wards lack sufficient space and infants are treated in big multi-patient wards, as opposed to private ones that guarantee more comfort for both infants and their parents.

The relationship between stress and an increase in PTSD symptoms was not emphasised in this study. What was highlighted was a connection between stress linked to sights and sounds in NICUs and PTSD symptoms in intrusion and avoidance groups with overall deterioration of PTSD, which seems to be a logical consequence and remains relevant to reports in the literature [29-31].

Limitations of the study include the non-randomised selection of the respondents and the fact that the research material (including clinical information) was obtained only by means of self-report tools.

In the view of the authors, it is essential to identify the factors prefiguring an increase in the intensity of stress, as perceived by parents of infants treated in NICUs, in order to propose effective interventions aimed at the improvement of their mental health.

\section{CONCLUSIONS}

The Polish version of PSS:NICU is an accurate and reliable tool for the assessment of stress experienced by parents whose infants require treatment in NICUs. Scale PSS:NICU in the Polish adaptation should be disseminated to all neonatal units.

\section{REFERENCES}

1. Lothian JA. The Journey of Becoming a Mother. JPE. 2008;17(4): 43-7. doi: 10.1624/105812408X364071.

2. Busse M, Stromgren K, Thorngate L, Thomas KA. Parents' Responses to Stress in the Neonatal Intensive Care Unit. CCN. 2013; 33(4): 52-9. doi: $10.4037 / \operatorname{ccn} 2013715$. 
3. Feeley N, Gottlieb L, Zelkowitz P. Mothers and Fathers of Very Low-Birthweight Infants: Similarities and Differences in the First Year After Birth. JOGNN. 2007; 36(6): 558-67. doi: 10.1111/j.15526909.2007.00186.x.

4. Gondwe KW, Holditch-Davis D. Posttraumatic stress symptoms in mothers of preterm infants. IJANS. 2015; 3: 8-17. doi: 10.1016/j. ijans.2015.05.002.

5. Lefkowitz DS, Baxt C, Evans JR. Prevalence and Correlates of Posttraumatic Stress and Postpartum Depression in Parents of Infants in the Neonatal Intensive Care Unit (NICU). J Clin Psychol Med Settings. 2010; 17(3): 230-7. doi: 10.1007/s10880-010-9202-7.

6. Morawski Mew A, Holditch-Davis D, Belyea M, Shandor Miles M, Fishel A. Correlates of Depressive Symptoms in Mothers of Preterm Infants. Neonatal Network: J Neonatal Nurs. 2003; 22(5): 51-60. doi: 10.1891/0730-0832.22.5.51.

7. Witt WP, Litzelman K, Spear HA, Wisk LE, Levin N, McManus BM, et al. Health-related quality of life of mothers of very low birth weight children at the age of five: Results from the newborn lung project statewide cohort study. Qual Life Res. 2012; 21(9): 1565-76. doi: 10.1007/ s11136-011-0069-3.

8. Vigod SN, Villegas L, Dennis C-L, Le Ross. Prevalence and risk factors for postpartum depression among women with preterm and low-birthweight infants: A systematic review. BJOG: IJOG. 2010; 117(5): 540-50. doi: 10.1111/j.1471-0528.2009.02493.x.

9. McManus BM, Poehlmann J. Maternal depression and perceived social support as predictors of cognitive function trajectories during the first 3 years of life for preterm infants in Wisconsin. Child: Care, Health and Development. 2012; 38(3): 425-34. doi: 10.1111/j.13652214.2011.01253.x

10. Miles MS, Funk SG, Carlson J. Parental Stressor Scale: neonatal intensive care unit. Nurs Res. 1993; 42(3): 148-52.

11. Guillaume S, Michelin N, Amrani E, Benier B, Durrmeyer X, Lescure $S$, et al. Parents' expectations of staff in the early bonding process with their premature babies in the intensive care setting: A qualitative multicenter study with 60 parents. BMC Pediatr. 2013; 13(1): 18 doi: 10.1186/1471-2431-13-18.

12. Turan T, Başbakkal Z, Özbek S. Effect of nursing interventions on stressors of parents of premature infants in neonatal intensive care unit. JCN. 2008; 17(21): 2856-66. doi: 10.1111/j.1365-2702.2008.02307.x.

13. Abdeyazdan Z, Shahkolahi Z, Mehrabi T, Hajiheidari M. A family support intervention to reduce stress among parents of preterm infants in neonatal intensive care unit. Iranian JNMR. 2014; 19(4): 349-53. Available from: http://www.ncbi.nlm.nih.gov/pmc/articles/ PMC4145487/.

14. Ahn Y-M, Kim N-H. Parental Perception of Neonates, Parental Stress and Education for NICU Parents. ANR. 2007; 1(3): 199-210. doi: 10.1016/S1976-1317(08)60022-5.

15. Beheshtipour N, Baharlu SM, Montaseri S, Razavinezhad Ardakani SM. The Effect of the Educational Program on Iranian Premature Infants' Parental Stress in a Neonatal Intensive Care Unit: A Double-Blind Randomized Controlled Trial. IJCBNM. 2014; 2(4): 240-50. Available from: http://www.ncbi.nlm.nih.gov/pmc/articles/PMC4201207/.
16. Franck LS, Cox S, Allen A, Winter I. Measuring neonatal intensive care unit-related parental stress. J Adv Nurs. 2005; 49(6): 608-15. doi: $10.1111 / j .1365-2648.2004 .03336 . x$.

17. Mansson C, Jakobsson U, Lundqvist P. Translation and psychometric evaluation of a Swedish version of the parental stressor scale PSS: NICU. Scand J Caring Sci. 2015; 30(1): 183-201. doi: 10.1111/scs.12217.

18. Hatcher L. A Step-by-step approach to using the SAS system for factor analysis and structural equation modeling. Cary: SAS Institute. 2009. XIV, 588.

19. Sperber AD. Translation and validation of study instruments for crosscultural research. Gastroenterology. 2004; 126: 124-128. doi: 10.1053/j. gastro.2003.10.016.

20. Montirosso R, Provenzi L, Calciolari G, Borgatti R. Measuring maternal stress and perceived support in 25 Italian NICUs. Acta Paediatrica. 2012; 101(2): 136-42. doi: 10.1111/j.1651-2227.2011.02440.x.

21. Miles MS, Holditch-Davis D, Schwartz AT, Scher M. Depressive symptoms in mothers of prematurely born infants. JDBP. 2007; 28(1): 36-44.

22. Chourasia N, Surianarayanan P, Adhisivam B, Vishnu Bhat B. NICU Admissions and Maternal Stress Levels. Indian J Pediatr. 2013; 80(5): 380-4. doi: 10.1007/s12098-012-0921-7.

23. Dudek-Shriber L. Parent Stress in the Neonatal Intensive Care Unit and the Influence of Parent and Infant Characteristics. AJOT. 2004; 58(5): 509-20. doi: 10.5014/ajot.58.5.509.

24. Lau C, Hurst NM, Smith EO, Schanler RJ. Ethnic/racial diversity, maternal stress, lactation and very low birthweight infants. J Perinatol. 2007; 27(7): 399-408. doi: 10.1038/sj.jp.7211770.

25. Turan T, Başbakkal Z, Özbek Ş. Effect of nursing interventions on stressors of parents of premature infants in neonatal intensive care unit. JCN. 2008; 17(21): 2856-66. doi: 10.1111/j.1365-2702.2008.02307.x.

26. Turner M, Chur-Hansen A, Winefield H, Stanners M. The assessment of parental stress and support in the neonatal intensive care unit using the Parent Stress Scale - Neonatal Intensive Care Unit. Women and Birth. 2015; 28(3): 252-8. doi: 10.1016/j.wombi.2015.04.001.

27. Franck LS, Oulton K, Nderitu S, Lim M, Fang S, Kaiser A. Parent Involvement in Pain Management for NICU Infants: A Randomized Controlled Trial. PEDIATRICS. 2011; 128(3): 510-8. doi: 10.1542/ peds.2011-0272.

28. Alkozei A, McMahon E, Lahav A. Stress levels and depressive symptoms in NICU mothers in the early postpartum period. J MATERN-FETAL NEO M. 2014; 27(17): 1738-43. doi: 10.3109/14767058.2014.942626.

29. Garfield L, Holditch-Davis D, Carter CS, McFarlin BL, Schwertz D, Seng JS, et al. Risk Factors for Postpartum Depressive Symptoms in Low-Income Women With Very Low-Birth-Weight Infants. Adv Neonatal Care. 2015; 15(1): 3-8. doi: 10.1097/ANC.0000000000000131.

30. Greene MM, Rossman B, Patra K, Kratovil AL, Janes JE, Meier PP. Depression, Anxiety, and Perinatal-Specific Posttraumatic Distress in Mothers of Very Low Birth Weight Infants in the Neonatal Intensive Care Unit. JDBP. 2015; 36(5): 362-70. doi: 10.1097/DBP.0000000000000174.

31. Shaw RJ, St John N, Lilo E, Jo B, Benitz W, Stevenson DK, et al. Prevention of Traumatic Stress in Mothers of Preterms: 6-Month Outcomes. PEDIATRICS. 2014; 134(2): 481-488. doi: 10.1542/peds.2014-0529. 